\title{
Collaboration and commitment in a regional supermarket supply chain
}

\author{
Rebecca Dunning * \\ North Carolina State University
}

Submitted January 18, 2016 / Revised March 19 and April 19, 2016 / Accepted April 20, 2016 /

Published online September 6, 2016

Citation: Dunning, R. (2016). Collaboration and commitment in a regional supermarket

supply chain. Journal of Agriculture, Food Systems, and Community Development, 6(4), 21-39.

http://dx.doi.org/10.5304/jafscd.2016.064.008

Copyright (C) 2016 by New Leaf Associates, Inc.

\begin{abstract}
This article presents findings from a longitudinal case study of efforts by a 100 -store regional grocery store chain to localize its supply of fresh produce. The study was conducted to better understand the development of collaborative supply chains between farmers and grocery stores, and the broader potential that grocery store chains might play in localizing food systems. Data consists of three years of the chain's local produce purchases via direct-store-delivery from farms to stores; a survey of store managers and farmervendors; and interviews with farmers and grocery store and chain-level management. Analysis is structured by a conceptual framework that links

\footnotetext{
* Rebecca Dunning, Center for Environmental Farming Systems, North Carolina State University; Raleigh, North Carolina USA; rebecca dunning@ncsu.edu

Disclosure

This material is based upon work supported by the National Institute of Food and Agriculture, U.S. Department of Agriculture (USDA), under award number 2013-68004-20363. Any opinions, findings, conclusions, or recommendations expressed in this publication are those of the author and do not necessarily reflect the view of the USDA.
}

collaboration to trust, which undergirds mutual commitment and mutual dependency between supply chain members, and which is dependent upon effective communication and positive prior market exchanges. The study finds that organizational structures constraining single-store autonomy in purchasing and pricing, coupled with supply variability from farms, limits trust-building and the establishment of mutual commitments and dependencies. These constraints, however, do not completely exclude direct-store-delivery as a strategy for food system localization and grower market diversification. Practitioners can support the building of collaborative supply chains through capacity-building and shepherding of early market exchanges between growers and stores, and supporting individual growers or groups of growers to become "preferred vendors" for regional grocery chains.

\section{Keywords}

Collaboration; Direct Store Delivery; Fresh Produce; Grocery Store; Logistics; Local Food; Supply Chain; Trust; Value Chain 


\section{Introduction}

The retail infrastructures of the alternative food system, including farmers markets, farm stands, and CSA (box) programs, provide channels through which small- and midscale farmers can more directly meet consumer demand for "local" food. Confronted with potential demand saturation in these direct-to-consumer markets (Low et al., 2015), small- and midscale farm enterprises (SMFEs) and practitioners in local-food system development have sought to link SMFEs into the "mainstream" market channels through which the vast majority of food is sold. Local food sold through intermediated market channels is often described in terms of SFME's "scaling-up" for larger markets (e.g., Day-Farnsworth, McCowan, Miller, \& Pfeiffer, 2009; Friedmann, 2007; Heiss, Sevoian, Conner, \& Berlin, 2015). One strategy to build cross-scale connections between SMFEs and larger buyers is for product to "piggy-back" on conventional distributional and retail infrastructure (Bloom \& Hinrichs, 2011; Clark \& Inwood, 2015).

Analyses of SMFE use of conventional food system infrastructure have been based on case studies at single points in time, typically over one year or one growing season, and rely on interviews and observational data (e.g., Abatekassa \& Peterson, 2011; Bloom \& Hinrichs, 2010, 2011; Clark \& Inwood, 2015; McCallum, Campbell, \& MacRae, 2014). These studies have identified the factors that constrain businesses operating at different scales from successfully engaging in market relationships. Trust between trading partners has been highlighted as a crucial prerequisite for relationship formation. This is true for both the food system literature, following from Stevenson and Pirog's work on "values-based supply chains" (2008), and business management research on the creation of "value chains" or "value systems" (Handfield \& Nichols, 2002).

This paper contributes to the literature on cross-scale food supply chains by tracing the attempts of a regional grocery store chain over a three-year period to localize its procurement of fresh produce, specifically examining the ability of SMFEs and a chain grocery store to forge and maintain trust and to invest in relationship-specific commitments that undergird mutually beneficial long-term business relationships. The analysis is based on store purchase data from SMFEs to the grocer for a baseline year and the subsequent three years of the initiative, and a survey of store managers and farmers engaged in direct-store delivery. Analysis of the quantitative data is complemented by qualitative data from interviews with farmers and grocery store management at the store and chain level, and observations by the author over the three-year period. This work addresses gaps in prior research about the exact means by which collaborative and robust trading relationshipsthose that are mutually beneficial and can withstand occasional disruptions_ — can be created and maintained over time. The analysis is of theoretical interest because it considers the context-dependent development of trust, and the organizational constraints that limit the evolution of trust into the commitments necessary for collaboration. The paper also offers advice to practitioners working to localize food systems via supply chain development.

The framework for this analysis is drawn from the supply chain management literature and its conceptualization of supply chain collaboration. The first sections of the paper review the theoretical and empirical literature on supply chain collaboration, both in general and specific to fresh produce. Then the focal grocery store chain and the data collection and research approach are described. Following this, the paper presents findings on the degree to which the grocery chain and local growers developed robust collaborative supply chain relationships, and the degree to which factors that the literature suggests contribute to collaborative supply chains were actually present in this case. The concluding sections of the paper discuss the implications of the findings for localfood producers seeking grocery chain markets and grocery store chains seeking to engage with local producers, and for technical assistance providers working to strengthen cross-scale trade between SMFEs and grocery stores.

\section{Supply Chain Management and Collaboration}

Supply chain management as a business strategy has evolved over time from a focus on optimizing 
internal processes of a single entity — such as optimal inventory management and vendor selectionto include management and control across a set of businesses that jointly create a final product or service. Figure 1 illustrates a simple supply chain, with products, services, and payments exchanged along the chain from raw resource supplier to final customer. Supply chain management informs current business operations and relationships, and guides decision-making on expanding operations to other functional areas through vertical integration (Cox, 1999).

Supply chain collaboration means that business entities along the supply chain — such as input supplier, trucking company, manufacturing partners-seek to maximize the value of the final product or service through exchange of information and joint decision-making (Figure 2), and in doing so outperform competing supply chains. Supply chain collaboration has the potential to increase the efficiency and responsiveness of the supply chain and to lower overall cost and/or enhance quality, thus increasing the value of products or services (Cox, 1999, 2004; Lewis, 2002; Matopoulos, Vlachopoulou, Manthou, \& Manos, 2007). Collaboration can reduce transaction costs - the costs of discovering prices, negotiating contracts, and specifying details of transactions (Hobbs, 1996). Supply chain collaboration potentially offers the strategic benefits of vertical integration without the need for direct control through ownership. The emerging widespread use of Electronic Data Interchange and other information-sharing technologies, including the ubiquity of smartphones, has provided the technological means to build these relationships.

Businesses working collaboratively in such a manner have been referred to as members of a "value chain" (Fischer, 2013), "value system" (Handfield \& Bechtel, 2002; Handfield \& Nichols, 2002), and "strategic alliance" (Lewis, 2002). The term "value chain" in this literature follows from the original use of the term by Michael Porter (1985) to refer to the building of value internal to a single company, as a product or service moved through operational subsystems from inbound logistics to sales and service.

Research has identified a consistent set of interpersonal and process factors critical to forming and maintaining collaborative ties over time. Collaboration is characterized by high levels of mutual trust and mutual commitment (Fischer, 2013; Holm, Eriksson, \& Johanson, 1999; Kwon \& Suh, 2004). Trust is defined as willingness to take

Figure 1. Simple Supply Chain

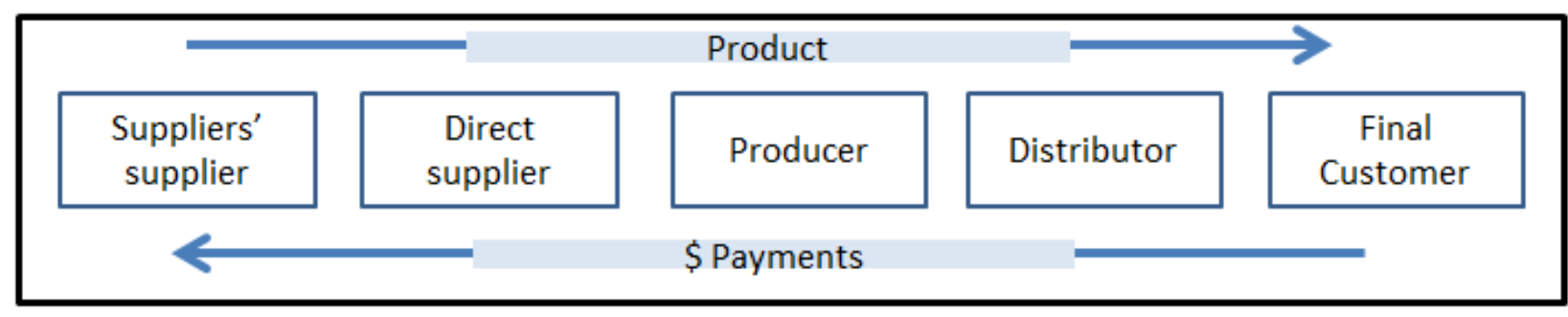

Figure 2. Collaborative Supply Chain

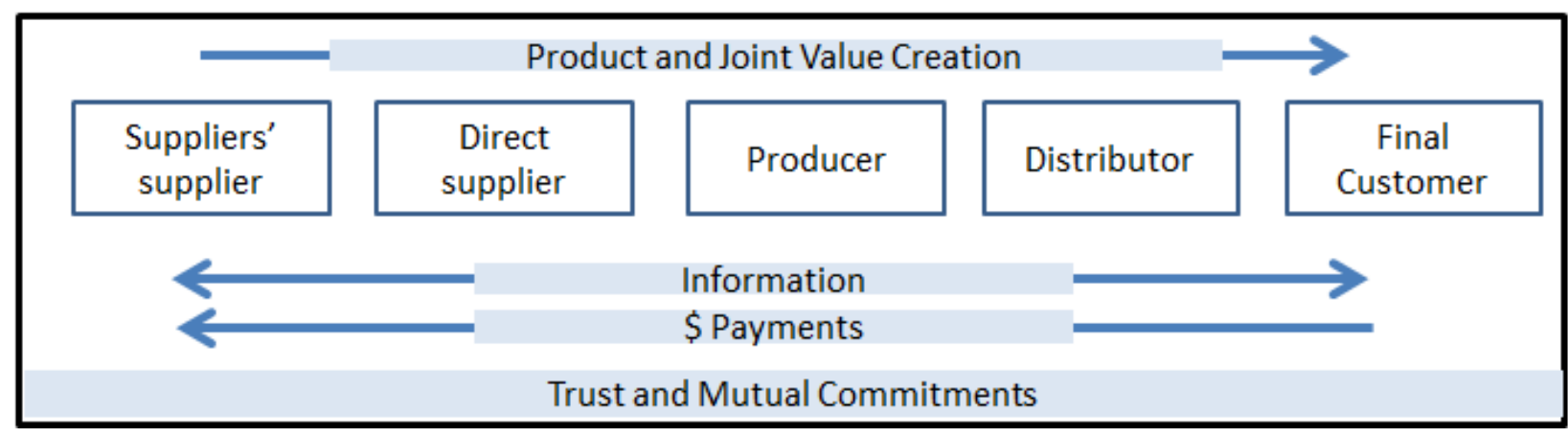


risks and in doing so to make oneself vulnerable to the actions of another, and arises when "one party has confidence in an exchange partner's reliability and integrity" (Morgan \& Hunt, 1994, p. 23). Key predictors of trust are perceptions of effective communication and instances of positive prior business exchanges (Fischer, 2013; Kwon \& Suh, 2004). By sharing sensitive information across the chain, partners can lower the costs of business operations (e.g., by lowering costs of held inventory) as well as signal their intention to remain in the relationship (Batt, 2003). Personal bonds such as friendship or familial ties do not have a direct bearing on trust (Fischer, 2013; Kwon \& Suh, 2004), but may indirectly enhance trust by promoting effective communication (Fischer, 2013).

The existence of a trusting relationship based on prior positive business exchanges and effective communication, however, does not ensure longterm collaboration. Long-term relationships form when businesses make commitments: relationshipspecific investments toward joint projects that increase the business viability of each entity by increasing the overall competitiveness of the supply chain (Handfield \& Nichols, 2002; Holm et al., 1999). Relationship-specific investments arise when trust is present, the relationship is seen as beneficial to both parties, and parties expect the relationship to continue in the future (Hammervol, 2011; Holm et al., 1999; Kwon \& Suh, 2004; Matopoulos et al.,
2007). Thus, trust alone does not ensure robust collaboration. Rather, trust creates the environment in which commitments can be made in the form of relationship-specific investments that lead to robust collaboration. These investments can take multiple forms, including the commitment of time for joint meetings to plan production, sharing of operational and strategic information such as scheduling or marketing plans, and joint participation in information-exchange platforms such as integrating inventory-management systems. Trust and mutual investments in the relationship are selfreinforcing, and contribute to long-term collaboration.

As commitments grow, a level of mutual dependence may arise. Dependence in the relationship varies according to the extent to which a trading partner supplies products or services for which there are few alternatives (Duffy \& Fearne, 2004). Mutual dependency means that both entities will be significantly harmed if the relationship ends. In this sense, a relationship characterized by both mutually beneficial gains and mutual dependence may simultaneously offer the most benefits, but can be the most difficult to maintain and carries the most risk if disrupted.

Figure 3 summarizes these findings from the supply chain research literature on collaboration into a conceptual model which links effective communication and prior successful business

\section{Figure 3. Theoretical Model of the Development of Collaborative Relationships in a Product Supply Chain}

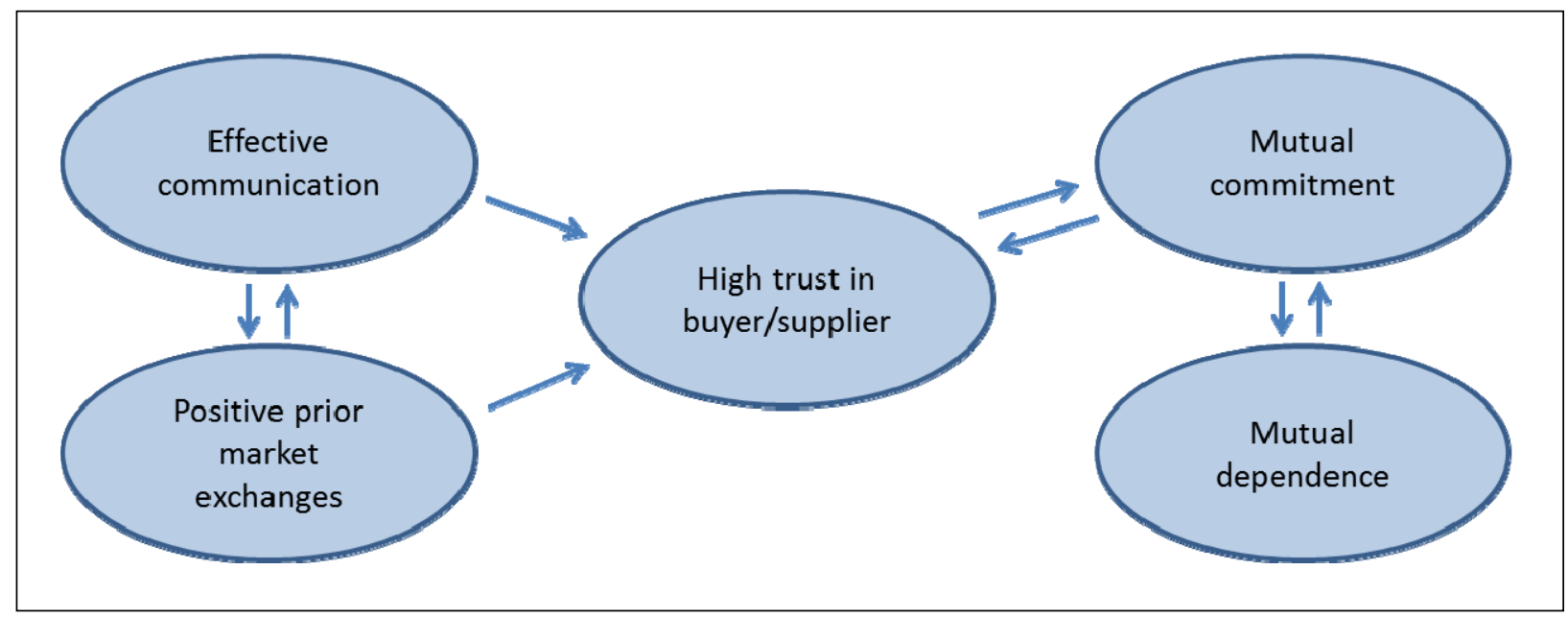

Based on findings from Fischer (2013); Holm, Eriksson, \& Johanson (1998); Kwon \& Suh (2004); and Morgan \& Hunt (1994). 
exchanges with the creation of trust. The existence of relationship trust sets the stage for forging relationship-specific commitments, which feeds back to reinforce trust and may lead to mutual dependencies.

Early research on supply chain collaboration arose from just-in-time manufacturing practices used to reduce held inventory. The particular characteristics of agricultural production, such as the volatile nature of prices and supply and the lack of brand identity for commodity products, make it more difficult to establish cross-chain collaborative relationships in this sector (Fischer, 2013; O'Keefe, 1998; White, 2000). Where collaboration in fresh produce supply chains has been found to exist, the same set of factors discussed above-information exchange, trust, and mutual commitments-have been present (Clements, Lazo, \& Martin, 2008). These collaborative relationships tend to be limited to operational and logistics-related activities between buyers and preferred vendors, rather than more strategic activities such as product development (Matopoulos et al., 2007).

\section{The Grocery Store Chain}

Grocery retailers consider "local" produce as a differentiation strategy in order to compete with rivals, notably supercenters (Karst, 2015; Webber, 2015). With fresh produce one of the few categories that can induce shoppers to switch stores (Fearne \& Hughes, 1999), grocers seek to take advantage of consumer perceived associations between "local" and "fresh" (Burt, Goldblatt, \& Silverman, 2015; Fearne \& Hughes, 1999; Fearne, Hughes, \& Duffy, 2001). Grocers use local offerings to build customer loyalty and attract new shoppers. This was the case for the 100 -store regional grocery store chain considered for this study and its initiative to localize procurement of fresh produce.

The grocery chain has its headquarters in the Mid-Atlantic region, with approximately 100 stores primarily clustered in metro areas in the Carolinas. It is affiliated through joint ownership with a regional grocery distribution center. The chain defines local produce as that grown within the same state as the store location, and regional produce as grown in a state adjacent to the store location.
Over the study period (2012-2015), approximately $98 \%$ of the value of fresh produce sold in the chain's stores was ordered from the affiliated distributor. Of this amount, the distributor purchased approximately 20\% from Carolina-based grower-shippers (i.e., those with substantial owned or leased acreages in the Carolinas but also purchasing produce as far south as Florida and north as New York state). Much of the remainder was sourced from California, Mexico, and South America. The grocer and distributor had contracts for select year-round high-volume items, such as bananas and bagged salad. For most products, however, the wholesaler had one or two preferred vendors and a set of back-up vendors.

Produce and all other items in the warehouse are managed, in the words of the chain producecategory manager, through "SKU rationalization," which refers to the merits of adding, retaining, or deleting Stock Keeping Units (SKUs), the numbered identifiers unique to each product. A store, and thus its warehouse supplier, have multiple SKUs associated with produce items - for example, separate SKUs for a slicer tomato, Roma tomato, vine-ripe tomato, etc., all sold by the pound and tagged with particular PLU codes that are standard to the industry. The warehouse also carries SKUs associated with UPC produce items that are sold by packaged unit rather than by pound or by piece, such as cherry tomatoes in plastic clamshells or other bagged fruits and vegetables. "Rationalization" means that the wholesaledistributor carries SKUs if the volume of that product warrants a slot space in warehouse inventory. Products that do not have sufficient volume will not be allocated a separate SKU or slot. The produce manager at the chain's affiliated grocery distributor noted that the limited seasonal availability of local (within state) produce items, combined with insufficient demand for "local" as a separate identifier, precluded dedication of separate warehouse slots based on product origin. Instead, produce in a particular slot becomes local when the combination of price and consistent availability and quality of locally grown produce offers better value than alternatives.

An alternative to warehouse aggregation and subsequent delivery to stores is the logistics 
practice of direct-store-delivery (DSD), whereby suppliers deliver product directly to stores without warehouse intermediation. Beer, branded snack foods, milk, bread, and other DSD items constitute an estimated $24 \%$ of unit volume sold in grocery stores (GMA, 2008). For retailers, direct-storedelivery offers faster replenishment cycles (minimizing a product being out-of-stock), reduces inventory held at the store level, and can reduce the delivery cost of the good by foregoing intermediate wholesalers. Beyond these logistics advantages, DSD relationships allow buyers and vendors to communicate and collaborate on product selection and sales, including information exchange on consumer preferences. Additionally, vendors engaged in DSD can observe how the product is merchandized in the store and suggest different placements, and vendors can use deliveries as opportunities to gather information on their competition (GMA, 2011; Otto, Schoppengerd, \& Shariatmadari, 2009).

Beginning in early 2013, the focal grocer, in conjunction with and support from a multi-year university initiative, began a concerted effort to source more products from SMFEs located in close proximity to stores. The grocer was motivated by a desire to differentiate from competitors by offering local, source-identified products. While the initiative is ongoing and has included sourcing of local protein and dairy products, the biggest shift in procurement practices, based on the number of individual farmers and stores affected, has been in DSD purchasing arrangements between grocery stores and individual produce farmers.

\section{Data and Research Method}

Three data sources were drawn upon for this investigation of collaborative supply chain development over a three-year time span at the grocery store chain. The primary data source consists of the store-level purchases of produce from SMFEs between 2012 (the year prior to the local sourcing initiative) and September 2015. The data include all DSD transactions between farmer-vendors and stores. For consistency, comparisons are made for the January-September time period for each year. Analysis of this data indicates the degree to which DSD relationships were consistent, grew, or declined over time. To avoid disclosing sensitive business information, presentation of sales volume and change over time relies on counts and medians rather than totals and mean values.

The second data source consists of web surveys fielded to produce managers and direct-storedelivery produce vendors between September and November 2014, at the approximate mid-point of the study period. The survey was primarily designed to ascertain relationship satisfaction of buyers and farmer-vendors and provide an anonymous means by which these trading partners could express their needs to university and grocery staff working in partnership on the initiative. To inform the study of supply chain collaboration, this paper draws on each partner's responses to statements concerning their perceptions of their trading partner's trustworthiness and reliability, and their own satisfaction with the current level of communication. Respondents indicated agreement on a sevenpoint Likert scale (strongly agree, somewhat agree, agree, neither agree nor disagree, somewhat disagree, disagree, and strongly disagree) to statements related to these perceptions.

The producer survey was distributed to the 36 DSD farmer-vendors who had supplied fresh produce to one or more of the chain stores over the prior six months, with 27 (75\%) responding. Farmer-respondents had been growing produce for an average of 11 years, and selling DSD to the grocery chain for an average of 2.2 years. Fiftyseven percent of respondents also sold product at a farmers market, and 54\% had an on-farm stand. The produce manager survey was distributed to all 76 produce managers who had purchased produce via DSD from farmers over the prior six months, with $32(42 \%)$ responding. Both manager and farmer surveys were anonymous, and thus responses cannot be matched. Managers responding to the survey had been purchasing directly from local farmers for an average of eight years, with seven $(22 \%)$ in their first year of purchasing local products and an equal number noting that they had been purchasing produce off and on from local farmers for more than 15 years.

The third data source is qualitative data from observations and interviews by the author, which supplements the quantitative data. Throughout the study period the author was involved on a weekly 
basis in an initiative to build cross-scale supply chain links between small- and midscale growers (defined as farms with gross receipts $<\$ 1 \mathrm{M}^{1}$ ) and large-scale buyers, including the focal grocery store chain. This work included telephone calls, site visits (e.g., to the regional warehouse, grocery stores, and farms), and meetings with grocery store and produce managers, the grocery chain produce category manager and local purchasing accounts manager, the regional warehouse manager and buyers, and numerous small- and midscale farmers. Interactions with these supply chain actors also included periodic semistructured interviews designed to ascertain the status of relationships across the chain. Quotes presented in the text below are drawn from an interview set of six farmers, the grocery chain produce category manager, and three store produce managers, all interviewed in September and October of 2015. The selection of farmers for these interviews was made so as to reflect the experiences of those who had been engaged in DSD relationships for at least two years, as well as farmers who had sold DSD at some point but no longer had a market relationship with stores. Stores that were actively buying DSD product and those that had lapsed in purchasing were also included.

Based on findings in the collaborative supply chain research literature, as summarized in Figure 3 , we can expect that robust supply chain relationships between store managers and SMFEs are more likely to exist when (1) store/produce managers and farmer-vendors are satisfied with the quality and frequency of their communication, (2) successful prior market exchanges exist, (3) perceptions of trust are high, (4) there is evidence of mutual commitments made in the relationship, and (5) there exist dependencies in the relationship. Additionally, support for the idea that grocery store chains can play an active role in food system localization would be indicated by overall growth in the number of SMFEs engaged in DSD relationships, the number of stores having DSD relationships with SMFEs, and the value and diversity of fresh, local produce items purchased.

\footnotetext{
${ }^{1}$ All mentions of currency in this paper are US\$.
}

\section{Setting the Stage for Collaboration}

As noted in the research review, robust relationships are more likely to be built on a foundation of positive prior exchanges. The grocery chain in this study took a number of measures to lower the barriers to entry for smaller-scale farmers seeking to sell directly to stores, and worked with new farmer-vendors to shepherd initial exchanges. With matched funding from its university partner, the chain hired a full-time local purchasing accounts manager to sign on local produce vendors. The chain developed, piloted, and institutionalized use of a simple four-page local vendor application to vet growers wishing to deliver to one or more stores. At the grocery chain's annual meetings in 2013 and 2014, chain-level management encouraged store managers to buy local products. The produce category manager and local accounts manager participated in university and agricultural Extension-sponsored grower-buyer meetings that brought them face-to-face with small- and midscale growers, which resulted in a number of trading relationships. These face-to-face meetings, a simple application process, and having a dedicated person at the corporate office created a vetting and initial sign-up process specific to DSD and SMFEs.

At the store level, local DSD produce vendors were permitted to bring product through the front door rather than through the receiving department; the latter has restricted hours and can get backed up with snack and beverage deliveries. Invoices were submitted at the store level, sent to corporate accounting, and farmers were issued checks within about two weeks of product delivery. Farmers were also offered the opportunity to showcase their products at store Community Table events at no charge. (Stores with Community Tables hold three to five events a week; branded products are typically charged a several hundred-dollar fee to feature products at the table and to be highlighted in related advertisements.)

\section{Changes in Local DSD Purchasing Over Time}

As noted above, the grocery chain has been engaged in efforts to source produce from smallerscale growers in geographic proximity to stores since early 2013. Growth in the number of farmer- 
Table 1. Type and Number of Direct-Store-Delivery (DSD) Produce Vendors and Stores, Focal Grocery Store Chain, 2012-2015

\begin{tabular}{cccccc}
\hline Year & $\begin{array}{c}\text { Total DSD } \\
\text { produce vendors }\end{array}$ & Total DSD stores & \multicolumn{2}{c}{ Number of DSD vendors additions (losses) of vendors by year and type of grower } \\
\hline 2012 & 5 & & Single-fruit crop & $\begin{array}{c}\text { Diversified vegetables } \\
\text { Food hub (primarily } \\
\text { mixed vegetables) }\end{array}$ \\
\hline 2013 & 20 & 38 & 4 & 0 & 1 \\
\hline 2014 & 36 & 62 & 3 added & 11 added & 2 added \\
\hline 2015 & 30 & 76 & 1 added & 12 added & added \\
\hline
\end{tabular}

vendors, number of stores buying from vendors, sales value, and diversity of products would indicate that stores achieved their objective. These increases would also indicate the capacity for conventional grocery store chains to serve as retail infrastructure for local-food systems.

Descriptive statistics (Table 1) find positive changes in each of these measures. In 2012, the chain had five vendors serving 38 stores, with 32 of the stores served by one of four single-fruit vendors of peaches, apples, or berries. In 2013, the chain had 20 vendors serving 62 stores, and most vendors were small- and midscale diversified vegetable operations. By 2014 there were 36 vendors serving 76 stores. In 2015 the number of vendors and stores dipped to 30 and 70, respectively; the decrease in vendors is largely due to poor growing conditions in the 2015 summer season, and the related inability or lack of desire by growers-given their more profitable direct-to-consumer market channels-to service stores. The addition and then loss of food hubs between 2013 and 2015 were due to hubs being added as vendors to provide summer CSA-style produce boxes to select stores in 2014. Over the last three years the grocer has experimented with different ways to source local products for its summer box program, with the boxes packed at an aggregator (food hub or other produce distributor) and delivered either DSD to stores or through the warehouse for purchase by shoppers. This program moved to centralized sourcing through a single produce distributor in 2015.

As the number of farmer-vendors selling via DSD grew from five to 30 (with a high of 36 in 2014), the proportion of stores buying from at least one local produce vendor grew from $38 \%$ of stores (38 of 100 stores) in 2012 to $70 \%$ in 2015, with a high of $76 \%$ in 2014 . In dollar terms, local produce purchasing increased approximately $500 \%$ over this time period (dollar figures are not disclosed, to maintain business confidentiality), with a high in 2014 and dipping slightly in 2015. DSD purchases comprise a small portion of the grocer's overall produce purchasing, comprising less than $3 \%$ of overall produce purchases in 2015. Regional produce procurement during the summer season of May to September, defined as produce grown in the chain home state and adjoining states, grew from $28 \%$ of total fresh produce purchased in 2012 to approximately $40 \%$ in 2015.

Table 2 provides descriptive statistics to characterize DSD transactions over time and compared to a baseline in 2012. From the standpoint of growers, the median number of stores remained stable, with most farmers delivering to about four stores, but some delivering to as few as one store and others to as many as 25 . The median annual number of DSD deliveries by produce vendor decreased from 44 to 28 between 2012 and 2015, and the range gradually increased, with number of deliveries for vendors ranging from six to 112 in 2014, and two to 320 in 2015. The median value of DSD sales by vendor decreased over the time period, from $\$ 19,242$ in 2012 to $\$ 8,206$ in 2015 . As discussed in more detail below, the median number of transactions, median dollar value for each transaction, and total median value of DSD sales by vendor decreased over time because each of these figures is lower for diversified vegetable growers than for single-crop fruit vendors. Between 2012 and 2015, the number of small- and midscale diver- 
Journal of Agriculture, Food Systems, and Community Development

ISSN: 2152-0801 online

www.AgDevJournal.com

Table 2. Direct-Store-Delivery (DSD) Produce Purchases by Focal Grocery Store, 2012-2015, January-September (all currency is US\$)

\begin{tabular}{|c|c|c|c|c|}
\hline & 2012 & 2013 & 2014 & 2015 \\
\hline Number of DSD farmer-vendors & 5 & 20 & 36 & 30 \\
\hline Number of stores receiving DSD deliveries & 38 & 62 & 78 & 70 \\
\hline Median number of stores served by a vendor & 4 & 4 & 4 & 3 \\
\hline Range in number of stores served by a vendor & $1-20$ & $1-24$ & $1-25$ & $1-25$ \\
\hline $\begin{array}{l}\text { Median number of DSD transactions per } \\
\text { vendor per year }\end{array}$ & 44 & 32 & 37 & 28 \\
\hline Median value of DSD sales by vendor & $\$ 19,242$ & $\$ 6,498$ & $\$ 7,907$ & $\$ 8,206$ \\
\hline Median number of DSD transactions per store & 6 & 6 & 8 & 11 \\
\hline Median value of DSD purchases per store & $\$ 2,394$ & $\$ 1,082$ & $\$ 1,535$ & $\$ 1,456$ \\
\hline $\begin{array}{l}\text { Median value of DSD store purchases per } \\
\text { transaction }\end{array}$ & $\$ 217$ & $\$ 189$ & $\$ 178$ & $\$ 122$ \\
\hline
\end{tabular}

sified produce vendors grew from zero to 21 . As the number of vegetable growers increased, the median value calculated across all growers decreased accordingly. It is important to note that the dollar value of DSD sales for individual vegetable growers did not have a pattern of decreasing over time. In most cases vegetable growers who sold in multiple years either maintained or increased their sales.

From the standpoint of stores, most stores had a relatively small number of DSD deliveries per year, though this increased from six in 2012 and 2013 to 11 in 2015 . The number of transactions per store (i.e., the number of instances that the store purchased local produce) varied widely: in 2015, some stores had as few as two deliveries of DSD produce, while others had as many as 63 deliveries. The value of DSD purchases per store decreased over time, from $\$ 2,394$ per store in 2012 to $\$ 1,456$ in 2015 . This is attributable to more stores engaged in DSD transactions with diversified vegetable producers, whose sales volumes and values were less than those of single-fruit crop vendors. The median value of a DSD purchase fell over time for the same reason, with the typical transaction between a grower and store falling from $\$ 217$ for a delivery in 2012 to $\$ 122$ in 2015 .

As discussed above and displayed in Table 2, store-level purchasing and number of transactions increased overall. The value per transaction, number of transactions, and median annual sales fell on a per-vendor basis, due to the addition of mixedvegetable growers who sold smaller amounts to fewer stores. Table 3 compares transaction characteristics for single-fruit and mixed-vegetable vendors. Data on food hubs is included, with the caveat that food hub experiences are not directly comparable: in 2013 and 2015, food hubs acted as mixed-vegetable DSD suppliers to one or several stores, while in 2014 the bulk of food hub sales were made as arranged deliveries of CSA-style boxes of produce delivered to select stores for a set number of weeks.

Comparing the single-fruit and mixed-

Table 3. Direct-Store-Delivery (DSD) Produce Purchases by Focal Grocery Store by Vendor Type, 2012-2015, January-September (all currency is US\$)

\begin{tabular}{lccc}
\hline & Single Fruit & Mixed Vegetables & Food Hub \\
\hline Median number (range) of stores served by vendors & $6(1-25)$ & $3(1-15)$ & $4(1-14)$ \\
\hline Median number (range) of DSD transactions per store & $49(1-320)$ & $25(1-244)$ & $32(2-202)$ \\
\hline Median value of DSD sales by vendor & $\$ 12,855$ & $\$ 2,420$ & $\$ 5,374$ \\
\hline Median value of DSD sales per transaction & $\$ 254$ & $\$ 150$ & $\$ 149$ \\
\hline
\end{tabular}


vegetable vendors in the second and third columns of the table, single-fruit vendors served more stores, had many more transactions per store, and had a much higher total sales value and dollar value per delivery. For example, a blueberry grower drawing on over 100 acres (40 hectares) made twice-weekly deliveries to more than 20 stores over a four-week season. Diversified vegetable providers had fewer transactions per store, served fewer stores, and had smaller total annual sales. The produce category manager indicated that the perishability of soft fruits and lack of appropriate postharvest cooling and refrigerated transportation on smaller farms made it less likely that individual smaller-scale growers would be used as vendors to one or several stores. Select fruit growers, like the blueberry grower, were equipped with appropriate post-harvest handling equipment and had sufficient volume to be considered a preferred vendor by the grocery chain.

\section{Developing Collaborative Relationships}

\section{Prior Collaboration}

As summarized in Figure 3, research on collaborative supply chains has found that successful prior market exchanges and satisfaction with partner communication are key prerequisites to the building of trust between trading partners. As noted above, the grocery chain set the stage for collaboration by dedicating resources to initiate and support direct-store-delivery of produce as an encouraged practice for its stores. Between 2012 and 2013, the number of vendors increased from five to 25 , and by 2014 all 25 of these initial farmer-vendors were still selling to one or more stores.

Nevertheless, DSD purchasing was highly variable across participating stores, with individual stores purchasing as little as $\$ 150$ and as much as $\$ 9,122$ worth of product during January-September 2015. The decision to engage in a DSD relationship occurred primarily at the store level with the produce and/or store managers, and interviews with store managers and produce managers revealed varying levels of interest in working directly with farmers (which was always understood as requiring extra time in comparison to ordering produce from the warehouse), variation in manager perceptions of difference in quality or uniqueness of local products compared to warehouse offerings, and the demand-pull for local products that managers experienced from shoppers.

Manager views on local produce could be quite idiosyncratic. For example, management at two stores that had a DSD relationship with the same farmer of diversified vegetables and strawberries both bought vegetables from the producer, but one manager also purchased large quantities of local strawberries during the season. The second manager noted that he would never buy local strawberries because of short shelf life; "They won't last more than a day," he noted, comparing this to the long shelf life of the primarily California strawberries provided to stores by the warehouse. This may reflect a misunderstanding on the part of the store manager as to the true shelf life of local strawberries, or a difference in the turnover sales capacity of berries at his store compared to other stores. Whatever the specific reason, it does suggest that the context for collaboration, one where trust exists, and the possibility for DSD relationship formation varies from store to store and depends on store management: their understanding of customer demand for local product, and the quality and consistency of product, and whether the extra effort to source local product is perceived to be justified. As one produce farmer with 25 acres (10 hectares) noted, "Everything really depends on the produce manager: does the manager care, does he push the products....If they just want to do it the simple way and order from the warehouse they will do that, [and] then they don't want to talk on the phone to someone like me."

\section{Communication}

Satisfaction with communication has also been identified as a key prerequisite for robust collaborative trading relationships (Figure 3). In the fall 2014 survey, manager-buyer and farmer-vendor responses to questions about communication revealed overall satisfaction. Sixty-eight percent of manager-buyers agreed with the statement "Local farmers keep me well informed," and $67 \%$ of farmer-vendors agreed with the statement "I am satisfied with how often I communicate with my buyer." 
Interviews by the author with managers and vendors indicated that both groups believed that the optimal means of communication depended on what worked best for the manager, with the farmer adjusting to the desired mode of communication. A diversified vegetable grower with 50 acres (20 hectares) said, "Each store, each produce manager, is different. You have to see what works for them: some guys are real easy, some guys send us an email, some text, some give you their personal number, some want you to call the store."

Despite overall satisfaction with communication, low dependency on both sides created lapses in communication that could disrupt the market relationship for the current season or even longer. While farmers stated that they could make fairly accurate estimates within five to seven days of delivery, there is always the chance of a weather crisis or other disruptive event that may keep them from the fields. Managers did not see this variability in supply on the grower side as especially important because, with sufficient notice, the store could order product from the warehouse. Grocer reliance on the warehouse as a backup was understood by growers: "Local is something that could be available, and then all of a sudden it is not available," said one grower.

Both managers and growers noted that when produce became available at lower cost from other regions (due to seasonal peaking), the trading relationship would be disrupted and could lead to managers losing touch with growers over a severalweek period. One store manager described his purchasing of local product as "hit or miss." A produce manager describes a not unusual chain of events: "I did not call [the grower] for a few weeks when I got his [product] list, and then he did not call me...I have a lot going on... [later in the season] I called him to get [local] product for an event, but he did not call me back until the day before so I could not order [from him]."

On the grower side, if a grower did not have product available for several weeks and then tried to reconnect with the store manager, it could take a few weeks to re-establish a rhythm of ordering. The store practice of only the store produce manager being authorized to make DSD orders could also lead to a relationship disruption. Said one vegetable grower: "Sometimes the produce manager is off for a couple of days, and by that time, you are looking at the next delivery."

Movement of store managers from one store to another was fairly common and could also lead to disruptions. Sometimes this served as a means by which vendors could increase the number of stores served, with the vendor continuing to serve a manager's prior store and also serving the new store. Because local growers were not viewed as critical suppliers to stores, however, farmers were uncertain as to whether or not the new manager would buy product from them. Again, this points to a "hit or miss" type of relationship, rather than one of partners working in close collaboration.

Farmers generally did not know in advance when warehouse prices would drop, or when the warehouse might enact a "force-out," a situation when buyers at the warehouse strike a good deal on an item, purchase the item, and then make shipments to stores whether or not they have made orders. The warehouse might get a "good deal" on greens, for example, and force-out shipments to the stores along with directions on how to merchandize the products and price them in accordance with the accompanying newspaper circular advertisements. Unanticipated produce force-outs make it extremely difficult for growers and store managers to plan transactions with certainty, regardless of the frequency or quality of their communication.

Because advertisements are the same across the chain's stores, managers cannot charge a different retail price even if their local purchase price is more or less than that of the warehouse. While store managers have the discretion to pay local producers more than the warehouse price, there is risk to the store of doing so, and the corporate produce-category manager discourages this practice; most store managers pay the same price as they would for a like item from the warehouse.

Consistency of communications was high for one class of growers: those providing a single fruit item, such as blueberries and peaches, over a relatively short season. Communications worked smoothly and consistently in these cases because the corporate produce-category manager had 
identified these SMFEs as preferred vendors for a product during a particular time window, and thus it was clear to store management that these were to be selected over any warehouse offerings during a defined period. These vendors typically delivered to more than ten stores on a weekly or twiceweekly basis during a several-week season.

\section{Trust}

In the fall 2014 survey, a high proportion of produce managers and farmers agreed with statements reflecting trust in their trading counterparts, with $93 \%$ of produce managers agreeing that "local farmers are trustworthy" and $85 \%$ of farmers agreeing that "[chain name] store managers are trustworthy."

In interviews, some farmers expressed frustration at prices received for their product, but did not attribute the prices to opportunism on the part of the grocer. One farmer said, "The produce managers understand my product and know it is ten times better, it is like night and day.... [but] if they get tomatoes out of Florida picked green they pay the same for mine as they pay for that." Yet farmers did not blame low prices on store-level management: "[the store] charge is whatever [the corporate office] wants them to charge, they don't really have the freedom to set the price."

It should be noted that despite dissatisfaction with prices compared to the alternative direct-toconsumer market (farm stands, CSAs), growers overall were very satisfied with the opportunity to sell directly to grocery stores. One grower interviewed had no desire to sell at farmers markets because of the time commitment. Selling DSD in small quantities (cases) allowed the grower to maintain his hydroponic tomato operation as an additional, profitable enterprise on his diversified produce, row crop, and poultry farm. When farmers were asked whether they would sell their product through other intermediaries, such as brokers, if direct-store sales were not available, three of the six farmers interviewed noted their preference for destroying their product rather than selling through a broker. One said, "I'd rather till it under," and another said, "We do not deal with brokers. I'll leave it in the field or cut it up or throw it away before I'll deal with a broker. The first year you deal with them it's great, then the second not so great, then the third year, the truck got rejected."

All farmers interviewed had a selection of market channels and viewed grocery stores as one among a set of alternatives. One grower said, "I won't bend over backwards to stock a store that is an hour away.... We do what we have to do to market [our products]." This farm had a successful farm stand and thus would have been foregoing a higher retail price at the stand compared to a lower price, plus transport costs, to sell to the grocer. Growers were also reluctant to make firm commitments for an entire season because of their own potential inability to meet demand, due to weather or other market commitments. One grower noted that in an excellent year he could probably supply 10 stores, but chooses to make firm commitments with just four: "It drives me crazy when I can't supply them, but I try to give them a heads up [on what I can supply]."

\section{Mutual Commitments and Dependency}

As defined in the supply chain research literature, commitments are tangible investments in specific business relationships. Long-term mutually beneficial trading relationships depend on the degree to which each partner makes commitments to the relationship (Holm et al., 1999; Morgan \& Hunt, 1994). The willingness to make commitments in a business relationship depends on trust, which includes perceived integrity and reliability of a trading partner.

The grocery chain made commitments in the form of a dedicated local-produce accounts manager and directives for stores to purchase from local farmers. Both farmers and buyers in DSD relationships expressed trust in their trading partner, but at the same time recognized that the actions of that partner were not completely reliable because of forces outside of the individual's control. Thus, for the most part, farmers and store-level management believed in the integrity of their trading partner, but not in their reliability. Produce managers recognized that unexpected events, primarily weatherrelated, could hamper the ability of farmers to supply products. Farmers recognized that storelevel managers were restricted by chain-level management, which influenced the volumes that 
could be ordered and the prices that could be paid.

While chain and store-level management wanted "local" products for their shoppers, the risk of dependence on locally sourced product outweighed the benefits. As the produce category manager summed it up, "I can't run out of yellow squash." Corporate and regional-level management noted that it was important not only to have stable quality (including size and shape) over time in any single store, but also across stores in an area. If a shopper bought a product one day at one store and two days later went to another of the chain's stores, the shopper should be able to find that same product. Centralized control at the regional and corporate level over procurement and marketing was designed to standardize quality and minimize the risk of errors, and their negative impact on profit, at the store level. Relying on produce from the chain regional distribution center was part of this standardization. While DSD produce had the benefit of source-identification, the variability in supply and quality from smaller growers meant that stores never came to depend on local produce. At the same time, diversified vegetable growers on small (less than 50-acre or 20-hectare) farms were also hesitant to make firm volume commitments, both because of weather events that could impact harvests, and farmer preferences to sell their limited supplies to their higher value direct-toconsumer markets.

Two exceptions to the lack of relationshipspecific investments and dependencies between stores and growers were observed. One was the case of single-item vendors of fruits such as berries and peaches. As noted above, communication about the volume of product and pricing was clear and consistent for these products because the decision to purchase was made at the chain level. Store management understood that the identified vendor would be the primary supplier-the preferred vendor - of the item for a specific period of time. Preferred fruit vendors serviced a large number of stores compared to diversified vegetable farms, had more frequent deliveries, and had higher total and per-transaction value (Table 3; discussion above). While these farmers had larger acreages than most of the DSD vendors, they were still single-family operations located in close proximity to one or more stores served, and thus were considered local farmers.

A second exception was the existence of multiyear relationships between single stores and single growers. A good example was a diversified vegetable and strawberry grower who began a relationship in 2013 with a single high-volume store. The store manager took a particular interest in sourcing local produce from this grower, and the range of products and total volume steadily increased over time. While the grower has also delivered to other stores in the chain, $90 \%$ of the sales to the chain are to this single store. The farmer described the relationship: "[the store manager] is good to me and I'm good to him, he is fair to me. I know that market, and when he needs it I am always there." The farmer participates in store events and product tastings several times per year, thus assisting the store in its local produce marketing. As a point of comparison to this, most store managers interviewed and observed during the study period expressed a view of local growers that was more neutral, requiring no ongoing commitment; as one manager said, "I am happy to buy local if they can get it to me [and] at the same price [as the warehouse]."

\section{Recommendations for Practitioners}

In prior research on cross-scale food supply chains, researchers and practitioners have suggested that collaborative relationships require trust (Abatekassa \& Peterson, 2011; Bloom \& Hinrichs, 2011; Clark $\&$ Inwood, 2015). As we have seen in this case, growers and buyers had interpersonal trust, believing in the inherent integrity of partners, but low confidence in the reliability of their trading partners, due to factors perceived as beyond their trading partners' control. Altering the institutionalized rules and practices that shape actors' decision-making in the fresh produce sector are beyond the scope of the current research. However, we can draw on this paper's findings to suggest ways in which practitioners and applied researchers can work around the edges of the institutionalized system of standards and practices to create more cross-scale connections.

One suggestion is continued support of grower upgrading. Upgrading activities for farmers selling 
to grocery stores include training about packaging and labeling requirements, appropriate post-harvest handling practices, and marketing; training and cost-sharing to achieve food safety certifications; and mini-grants for low-cost infrastructure for temperature and humidity management. Supply chain upgrading for small- and midscale producers is a core activity in international economic development and is designed to increase the value of smaller-scale farm products so that producers garner more income from their sale (Humphrey \& Schmitz, 2004). Growers, and service providers such as the extension personnel with whom they work, should also keep abreast of trends in packaging, marketing, and merchandising. For example, stores may be unwilling to stock a produce item in a loose form if a similar item is already at the warehouse and on store shelves, but if packaged in a unique clamshell or grab bag, the item becomes a differentiated product. (In addition, this packaging uses UPC codes rather than PLU codes, thus permitting differential pricing compared to loose items from the warehouse.) Another example of upgrading is to build a producer's brand through active social media; a social media following for a farm and product is a selling point for store managers because it shows that the grower's own marketing can drive shoppers to stores.

Another recommendation is to bring "ready" farmers together with buyers, with ready farms having sufficient acreage, packing and grading skills, food safety certifications, and transportation in place to service one or more stores. This means asking stores what their minimum requirements are for growers, and assisting stores in establishing a simple vetting process to identify ready and notready growers. Feedback loops between store or chain-level management and service providers can direct not-ready growers to the training and other support needed. Serving as a vetting intermediary between growers and stores lessons the possibility that store managers and local growers will have a poor first experience; as previously discussed, successful prior market relationships are a prerequisite for the creation of collaborative supply chains. A single negative experience potentially short-circuits sales to any of the stores in the chain.
Face-to-face networking of ready buyers with ready sellers can occur in speed-networking formats or through workshop panels featuring both buyers and the growers with whom they already work. Networking and peer learning can also take place in conjunction with training workshops on food safety and post-harvest handling, where buyers can contribute their expertise and advice and at the same time hear from growers about their experiences.

The focal grocer was able to broadly expand its local sourcing program because of dedicated staff with the grocery chain and at the university partner, which allowed ongoing exchange of information about particular growers and particular stores. This information was then generalized to support recruitment of stores and growers (e.g., the vendor signup process). Having ongoing links between individual grocery stores and local support providers, such as extension personnel, can be invaluable in facilitating connections and shepherding early collaborations. These support providers can draw on location-specific store needs in order to link growers to these needs. For example, one midscale produce grower interviewed for this study found that his products were in demand at rural groceries in his area not because they were branded "local" and source-identified, but because the grower could deliver small mixed loads of various produce items in-between larger loads from the warehouse. The grocery store desired smaller loads because of limited inventory space, and sourcing locally allowed it to have fresher product and reduce shrink (i.e., produce loss through decomposition). As discussed earlier in this paper, more frequent, smaller deliveries are one of the attractions of DSD as a supply-chain logistics practice, and one upon which local growers can capitalize.

Practitioners can also support individual growers and groups of growers in becoming preferred vendors. The term "preferred vendor" is sometimes used pejoratively when discussing consolidation in the grocery (and other food) sectors, as it implies that only large growershippers can achieve preferred status, which limits opportunities for small- and midscale farmers. As we saw in the case of this grocery store chain, 
however, local growers can become preferred vendors. Extension personnel and other local-food system practitioners can work with individual growers and facilitate horizontal collaborations among multiple growers, focusing on establishing consistent quality across growers to supply particular items to local/regional grocery chains over a season.

Applied researchers can contribute to crossscale links, farmer viability, and food localization by conducting surveys and interviews that objectively and anonymously gather information on trading partners' perceptions of the success of their relationships and to identify specific recommendations to enhance them. Researchers can also define quantitative metrics to gauge changes in procurement, identify the decisionmaking criteria at different levels of management that impact procurement decisions, and analyze the impact of change on the economic viability of growers. Furthermore, researchers can be attentive to the business literature on supply chain research and management tools, and apply these to the work of developing cross-scale local-food supply chains.

\section{Summary and Conclusion}

Bridging the scale differences between small- and midscale farm enterprises (SMFEs) and the food service and grocery retail outlets where most food is purchased has become a local-food- system building project undertaken by practitioners, and a topic of research among academics. This paper examined the experiences of one grocery store chain over a three-year period to increase procurement of local produce from SMFEs. This longitudinal case study examined direct-storedelivery as a logistics strategy to bring farmervendors and store-manager buyers into direct communication for the building of collaborative supply chain relationships. Based on prior research findings on collaborative supply chains, satisfaction with communication and positive past trading experiences build trust, which creates the context for partners' investments in a long-term business relationship.

Analysis of data over the three-year period found evidence of localization, with a substantial increase in the total number of DSD vendors, the number of stores buying from DSD vendors, and the variety of local-produce items. Judging by the case study data on the value of purchases by individual stores from individual farmers (median of $\$ 1,456$ in January-September 2015), however, the impact of using conventional food-system infrastructure as a means to localize food systems appears quite limited. Broadening the DSD program to all stores in a grocery chain, incentivizing managers to consistently offer selections of local products, and working collaboratively with single growers or a grower group so that they become preferred vendors are ways to increase the capacity of conventional grocery infrastructure to buy from, and depend on, local sources of fresh produce.

Managers at the store level and farmer-vendors expressed overall satisfaction with communication, but interviews revealed that communication frequently lapsed, negatively impacting the trading relationship. Farmers and store managers expressed confidence in the integrity of their counterpart in the relationship, suggesting the relationship was a trusting one. However, farmers and managers also expressed low confidence in reliability, which they attributed to factors outside their partners' control. This stymied the creation of relationship-specific investments upon which deeper collaborative business relationships could form. A deeper relationship, for example, would be one in which SMFEs and store buyers discuss and plan production for the following season and strategize about marketing and merchandising (Matopoulos et al., 2007).

Individual stores and farmers formed and maintained year-after-year trading relationships, but the data did not reveal strong commitments on the part of store manager-buyers or farmer-vendors. The relationships between most growers and storelevel buyers could be described less as collaborative, and more as conditional: growers contact stores if they have product available for sale at the anticipated purchase price (generally half of their direct-to-consumer sales price), and stores buy from growers if the manager has an interest in buying local and the product is offered at a price similar to that which can be procured from the 
warehouse. This is not necessarily negative: most growers that began DSD relationships with stores have continued to sell to them, and find selling to grocery stores to be a good addition to their portfolio of market channels.

Conditional relationships could be made more collaborative in nature with a more defined, ongoing, and institutionalized communication plan between corporate management, stores, and farmer-vendors, so that vendors could anticipate expected lapses in orders. More consistent communication coupled with a robust communications platform (e.g., scheduled calls or check-in emails, regardless of whether an order was anticipated) could increase perceptions of reliability.

The organization of supermarket chains, even smaller regional chains such as that considered in this study, can preclude formation of strong mutual commitments at the store level. Store-level managers are restricted in their decision making on both volume and pricing by chain-level management, with corporate management reacting to a dynamic global marketplace that drives it to take advantage of favorable buys at the warehouse level. The inherent variability in small- and midscale produce farming combined with the operating and marketing strictures at the corporate level restrict storelevel autonomy, limiting the ability of stores and farmers to truly collaborate.

There is little chance that chain stores will end their practice of seeking "deals" in volume, quality, and pricing in produce procurement. Improvements in logistics over the past 30 years have made virtually any produce item available in chain stores at any time of the year. This means that year-round availability is no longer a differentiator among stores, but considered by grocers to be a competitive necessity. Local, source-identified product is but one differentiator for store products, as are jumbo-sized peppers arranged in geometric displays or changing selections of exotic mixedvegetable stir-fry packs. Local growers can capitalize on the advantages of direct-store-delivery, but should not expect that the "local" attribute of their products will alone lead to buyer commitments and dependencies.

Reaching the status of a "preferred vendor," either at the individual store level where a strong collaborative relationship forms between a single farm and one to several stores, or at the chain level where a grower is identified as a preferred vendor of a particular local product for a defined period for a number of stores (as we saw with fruits), is achievable if store-level management has the incentive to invest in the relationship, and/or if disincentives that currently exist are minimized. Local single-fruit vendors offer nearly ripe product at competitive prices, have appropriate postharvest handling including cooling equipment to lengthen shelf life, and deliver these products directly to stores, offering the chain a competitive advantage over rivals. These fruit vendors gain by circumventing wholesalers and brokers to whom they had traditionally sold their product, thus garnering a higher price. Horizontal cooperation among growers to jointly become preferred vendors is a way to simultaneously enhance grower market power and localize food systems.

Despite the weakness of store-level commitments, the existence of a direct-store market channel for SMFEs was seen as desirable on both sides of the relationship. Store managers were interested and willing to commit the added time required to begin and maintain a relationship with local growers. Chain management continues to seek ways to bring more locally sourced product into more stores, but within the market strictures of the grocery sector. Practitioners and applied researchers can play an important role in completing a triangle of communications and support for SMFEs and for food system localization by facilitating networking among buyers and sellers, providing training and support from post-harvest handling to packaging to market channel analysis, and facilitating horizontal value-chain cooperation among growers to build their market power as preferred vendors.

\section{Limitations and Future Research}

The present study rests on the assumption that the benefits of localizing food production, distribution, and consumption outweigh potential disadvantages. Confirmation of this assumption is productand place-specific, however, and localization may result in increased economic and environmental costs (Atallah, Gómez, \& Björkman, 2014; Gómez 
\& Gao, 2011; Hauwermeiren, Coene, Engelen, \& Mathijs, 2007; Nicholson, Gómez, \& Gao, 2011; Nordmark, Ljungberg, Gebresenbet, Bosona, \& Jüriado, 2012). This study was confined to fresh produce grown in the Mid-Atlantic U. S., and to the actions of a single regional grocery store chain. A suggestion for future research is to compare the practices, experiences, and outcomes of this grocer's local-sourcing initiative to similar initiatives at entities with different organizational configurations; for example, with a chain of stores that does not have an associated distribution partner, or with chains that have contractual relationships with local-grower marketing cooperatives. One suggested conceptual framework for such a comparison is the one explicated in this paper-examining communication, trust (integrity and reliability), and the capacity for a context of trust to generate mutual commitments and dependencies.

\section{References}

Abatekassa, G., \& Peterson, H. (2011). Market access for local food through the conventional food supply chain. International Food and Agribusiness Management Review, 14(1), 41-60. Retrieved from http://ageconsearch.umn.edu/bitstream/100876/ 2/20081030 Formatted.pdf

Atallah, S., Gómez, M., \& Björkman, T. (2014). Localization effects for a fresh vegetable produce supply chain: Broccoli in the eastern United States. Food Policy, 49, 151-159. http://dx.doi.org/10.1016/j.foodpol.2014.07.005

Batt, P. (2003). Building trust between growers and market agents. Supply Chain Management, 8(1), 65-78. http://dx.doi.org/10.1108/13598540310463378

Bloom, J. D., \& Hinrichs, C. C. (2010). Moving local food through conventional food system infrastructure: Value chain framework comparisons and insights. Renewable Agriculture and Food Systems, 26(1), 13-23. http://dx.doi.org/10.1017/S1742170510000384

Bloom, J. D., \& Hinrichs, C. C. (2011). Informal and formal mechanisms of coordination in hybrid value chains. Journal of Agriculture, Food Systems, and Community Development, 1(4), 143-156. http://dx.doi.org/10.5304/jafscd.2011.014.016

Burt, R., Goldblatt, M., \& Silverman, S. (2015) Firmly rooted, the local food market expands. Chicago: A. T.
Kearney. Retrieved from https://www.atkearney. com/documents/10192/6773369/Firmly+Rooted + the + Local + Food + Marke $\% 20 \mathrm{t}+$ Expands.pdf $/ 863$ 737a6-0b44-40d0-b339-da25c4563dc3

Clark, J. K., \& Inwood, S. M. (2015). Scaling up regional fruit and vegetable distribution: Potential for adaptive change in the food system. Agriculture and Human Values, 33(3), 503-519. http://dx.doi.org/10.1007/s10460-015-9618-7

Clements, M., Lazo, R., \& Martin, S. (2008). Relationship connectors in NZ fresh produce supply chains. British Food Journal, 110(4/5), 346-360. http://dx.doi.org/10.1108/00070700810868898

Cox, A. (1999). Power, value and supply chain management. Supply Chain Management, 4(4), 167-175. http://dx.doi.org/10.1108/13598549910284480

Cox, A. (2004). The art of the possible: Relationship management in power regimes and supply chains. Supply Chain Management, 9(5), 346-356. http://dx.doi.org/10.1108/13598540410560739

Day-Farnsworth, L., McCowan, B., Miller, M., \& Pfeiffer, A. (2009). Scaling up: Meeting the demand for local food. Madison, Wisconsin: University of Wisconsin Cooperative Extension Agricultural Innovation Center \& UW College of Agricultural and Life Sciences Center for Integrated Agricultural Systems. Retrieved from http://www.cias.wisc. edu/wp-content/uploads/2010/01/baldwin_web_ find.pdf

Duffy, R., \& Fearne, A. (2004). Partnerships and alliances in UK supermarket supply networks. In M. A. Bourlakis \& P. W. H. Weightman (Eds.), Food supply chain management (pp. 136-152). Oxford, UK: Blackwell.

Fearne, A., \& Hughes, D. (1999). Success factors in the fresh produce supply chain: Insights from the UK. Supply Chain Management, 4(3), 120-131. http://dx.doi.org/10.1108/13598549910279567

Fearne, A., Hughes, D., \& Duffy, R. (2001). Concepts of collaboration: Supply chain management in a global food industry. In J. Eastham, L. Sharples, \& S. Ball (Eds.), Food Supply Chain Management: Issues for the Hospitality and Retail Sectors (pp. 55-89). London, UK \& New York, NY: Routledge.

Fischer, C. (2013). Trust and communication in European agri-food supply chains. Supply Chain Management, 18(2), 208-218. http://dx.doi.org/10.1108/13598541311318836 
Friedmann, H. (2007). Scaling up: Bringing public institutions and food service corporations into the project for a local, sustainable food system in Ontario. Agriculture and Human Values, 24(3), 389398. http://dx.doi.org/10.1007/s10460-006-9040-2

Grocery Manufacturers Association. (2008). Powering growth through direct store delivery. Washington, D.C.: Author. Retrieved from http://www.gmaonline. org/issues-policy/collaborating-with-retailers/ supply-chain-and-logistics/direct-store-delivery/

Grocery Manufacturers Association. (2011). Optimizing the value of integrated DSD. Washington, D.C.:

Author. Retrieved from http://www.gmaonline. org/issues-policy/collaborating-with-retailers/ supply-chain-and-logistics/direct-store-delivery/

Hammervoll, T. (2011). Governance of value creation in supply chain relationships. Supply Chain Forum, 12(2), 116-126.

http://dx.doi.org/10.1080/16258312.2011.1151726

Handfield, R. B., \& Bechtel, C. (2002). The role of trust and relationship structure in improving supply chain responsiveness. Industrial Marketing Management, 31(4), 367-382. http://dx.doi.org/10.1016/S0019-8501(01)00169-9

Handfield, R. B., \& Nichols, E. L. (2002). Supply chain redesign: Transforming supply chains into integrated value systems. Upper Saddle River, New Jersey: Financial Times Prentice Hall.

Hauwermeiren, A., Coene, H., Engelen, G., \& Mathijs, E. (2007). Energy lifecycle inputs in food systems: A comparison of local versus mainstream cases. Journal of Environmental Policy and Planning, 9(1), 3151. http://dx.doi.org/10.1080/15239080701254958

Heiss, S., Sevoian, N., Conner, D., \& Berlin L. (2015). Farm to institution programs: Organizing practices that enable and constrain Vermont's alternative food supply chains. Agriculture and Human Values, 32(1), 87 -97. http://dx.doi.org/10.1007/s10460014-9527-1

Hobbs, J. E. (1996). A transaction cost approach to supply chain management. Supply Chain Management, 1(2), 15-27. http://dx.doi.org/10.1108/13598549610155260

Holm, D. B., Eriksson, K., \& Johanson, J. (1999). Creating value through mutual commitment to business network relationships. Strategic Management Journal, 20(5), 467-486. http://dx.doi.org/10.1002/ (SICI)1097-0266(199905)20:5<467::AID$\underline{\mathrm{SMJ} 38>3.0 . \mathrm{CO} ; 2-\mathrm{J}}$
Howard, P.H. (2016). Consolidation in the food system: Who controls what we eat? London: Bloomsbury Academic.

Humphrey, J., \& Schmitz, H. (2004). Governance in global value chains. In J. Humphrey \& H. Schmitz (Eds.), Local enterprises in the global economy: Issues of governance and upgrading (pp. 95-109). Northampton, Massachusetts: Edward Elgar.

Karst, T. (2015, September 25). Independent retailers boost organic, local offerings. The Packer, p. B10. Retrieved from http://www.thepacker.com/ news/independent-retailers-boost-organic-localofferings

Kwon, I. G., \& Suh, T. (2004). Factors affecting the level of trust and commitment in supply chain relationships. Journal of Supply Chain Management, 40(1), 4-14. http://dx.doi.org/10.1111/j.1745493X.2004.tb00165.x

Lewis, D. J. (2002). Partnerships for profit: Structuring and managing strategic alliances. New York: Free Press.

Low, S., Adalja, A., Beaulieu, E., Key, N., Martinez, S., Melton, A., ... Jablonski, B. (2015). Trends in U. S. local and regional food systems: $A$ report to Congress (Report AP-068). Washington, D.C.: U.S. Department of Agriculture, Economic Research Service. Retrieved from http://www.ers.usda.gov/ publications/ap-administrative-publication/ap068.aspx

Matopoulos, A., Vlachopoulou, M., Manthou, V., \& Manos, B. (2007). A conceptual framework for supply chain collaboration: Empirical evidence from the agri-food industry. Supply Chain Management, 12(3), 177-186. http://dx.doi.org/10.1108/13598540710742491

McCallum, D., Campbell, A. M., \& MacRae, R. (2014). Can large retailers localize supply chains: A case analysis of the challenges facing one Canadian retailer. Journal of Agriculture, Food Systems, and Community Development, 4(1), 163-176. http://dx.doi.org/10.5304/jafscd.2014.042.015

Morgan, R. M., \& Hunt, S. D. (1994). The commitmenttrust theory of relationship marketing. Journal of Marketing, 58(3), 20-38. http://dx.doi.org/10.2307/1252308

Nicholson, C., Gómez, M., \& Gao, O. (2011). The costs of increased localization for a multiple produce food supply chain: Dairy in the United States. Food Policy, 36(2), 300-310. http://dx.doi.org/10.1016/j.foodpol.2010.11.028 
Nordmark, I., Ljungberg, D., Gebresenbet, G., Bosona, T., \& Jüriado, R. (2012). Integrated logistics network for the supply of locally produced food, Part II: Assessment of e-trade, economic benefit and environmental impact. Journal of Service Science and Management, 5(3), 249-262.

http://dx.doi.org/10.4236/jssm.2012.53030

O’Keefe, M. (1998). Establishing supply chain partnerships: Lessons from Australian agribusiness. Supply Chain Management, 3(1), 5-9. http://dx.doi.org/10.1108/13598549810200799

Otto, A., Schoppengerd, F. M., \& Shariatmadari. R. (2009). Success in the consumer products market — understanding direct store delivery. In R. Shariatmadari, F. M. Schoppengerd, \& A. Otto (Eds.), Direct store delivery: Concepts, applications and instruments (pp. 1-29). Berlin: Springer-Verlag.
Porter, M. (1985). Competitive advantage: Creating and sustaining superior performance. New York: Free Press. Stevenson, G. W., \& Pirog, R. (2008). Values-based supply chains: Strategies for agrifood enterprisesof-the-middle. In T. A. Lyson, G. W. Stevenson, \& R. Welsh (Eds.), Food and the mid-level farm: Renewing an agriculture of the middle (pp. 119-143). Cambridge, Massachusetts: MIT Press.

Webber, L. (2015, April 28). Give and take: Mixed blessings in fresh foods survey. Supermarket News, 34-40. Retrieved from http://supermarketnews.com/sn-research/giveand-take-mixed-blessings-fresh-foods-survey

White, H. (2000). Buyer-supplier relationships in the UK fresh produce industry. British Food Journal, 102(1), 6-17. http://dx.doi.org/10.1108/00070700010310605 